\title{
Virologic suppression and mortality of patients who migrate for HIV care in the province of British Columbia, Canada, from 2003 to 2012: a retrospective cohort study
}

Viviane Dias Lima ${ }^{1,2^{*}}$, Nicola Goldberg ${ }^{3}$, Lillian Lourenço ${ }^{1}$, William Chau', Robert S. Hogg ${ }^{4}$, Silvia Guillemi ${ }^{1}$, Rolando Barrios ${ }^{1}$ and Julio S G Montaner ${ }^{1,2}$

\begin{abstract}
Background: Migration among persons living with HIV (PLWH) seeking HIV care is common; however its effect on health outcomes in resource-rich settings is not well understood. We conducted a retrospective cohort study to quantify the extent to which PLWH are migrating for care within British Columbia (BC) and its association with virologic suppression and mortality.
\end{abstract}

Methods: Eligible PLWH first initiated treatment in BC between 2003 and $2012(N=3653)$. Analyses were performed at the regional Health Authority $(\mathrm{HA})$ level $(N=5)$. For privacy reasons, we kept the name of these HAs anonymous and we re-named these five regions as 1 to 5. PLWH were classified according to the HA where they resided and received HIV care. We calculated all-cause mortality rates, life expectancies (at age of 20 years), and in, out and net migration rates across HAs using different demographic methods. Virologic suppression ( $<50$ copies $/ \mathrm{mL}$ ) was based on the last viral load available for each PLWH. We also calculated per-capita rates (per 100 PLWH ever on CART) for each HA by dividing the number of PLWH by the number of physicians attending this population.

Results: There is considerable heterogeneity in physician availability across all HAs, with per-capita rates (per 100 PLWH ever on CART) ranging from 2.2 ( $\mathrm{HA} 1$ ) to 12.7 ( $\mathrm{HA}$ 3) based on the HA PLWH received care. We observed that in HAs 1 , 4, and 5, between 4 and $10 \%$ of PLWH migrated to HA 3 (i.e. the largest urban center) to receive care, and for HA 2 this proportion increased to $21 \%$. In HA 3, $77 \%$ of its PLWH residents remained in the same HA for their care. Migrating to a larger center for HIV care was not associated with higher rates of viral load suppression; it was significantly associated with lower mortality rates and higher life expectancies.

Conclusions: A thorough understanding of the reason(s) for these significant migration rates across BC will be critical to inform resource allocation and optimize the impact of HIV treatment.

\section{Background}

In the early days of combination antiretroviral therapy (cART), HIV treatment options and access was limited and treatment guidelines were relatively complex [1]. As a result, HIV care was resource intense and required a high level of provider expertise; as such, services tended

\footnotetext{
* Correspondence: vlima@cfenet.ubc.ca

'British Columbia Centre for Excellence in HIV/AIDS, 608-1081 Burrard Street, Vancouver, BC, Canada V6Z 1 Y6

${ }^{2}$ Division of AIDS, Department of Medicine, Faculty of Medicine, University of British Columbia, Vancouver, BC, Canada V6Z 1 Y6

Full list of author information is available at the end of the article
}

to be concentrated in specialized clinics in large urban centres. Since then, cART has evolved substantially, with an increased number of simplified, safer, bettertolerated and more effective treatment options [2]. The evolution of cART has made the goal of lifelong virologic suppression a realistic possibility, and has enabled the emergence of a bold new target for the global control of HIV/AIDS: the 90-90-90 Target [3]. In order to meet the 90-90-90 Target, persons living with HIV (PLWH) will necessitate regular access to an experienced care provider to fully adhere and benefit from treatment [4]. 
Since HIV is now considered a chronic manageable disease, therapeutic guidelines have been simplified and HIV care has increasingly shifted to decentralized communitybased medical practices $[5,6]$. Studies looking at patient outcomes for other chronic diseases have shown that access to community-based care offered by a continuous provider was associated with increased attendance at follow-up appointments and better disease control, which translated into fewer emergency department visits and hospitalizations, as well as decreased mortality [7-11]. Patients also reported higher satisfaction with their care when it is available locally and offered by a continuous provider or a team of providers $[7,11,12]$.

The success that cART has achieved in improving disease outcomes among PLWH can be potentially hindered by patient migration, since migration has been identified as a possible source of loss to follow up in several studies, particularly in resource-limited settings [13-22]. Typically, it has been reported that PLWH tend to migrate towards urban centres following an HIV diagnosis to seek treatment and care [23]. It has been suggested that this migratory pattern is driven by the increased HIV stigma and the lack of access to specialized medical care in small communities [24, 25]. Regardless of the reason, migration has been associated with incomplete adherence to cART and higher mortality $[26,27]$. However, the association of patient migration, especially when they routinely migrate for care, with cART outcomes in resource-rich settings is not well understood.

Migrating for care is particularly concerning given the existing evidence on the importance of communitybased continuous care for improving other chronic disease outcomes. We, therefore, conducted the present retrospective cohort study to quantify the extent to which PLWH are migrating for their care within British Columbia (BC), Canada, and its association with HIV virologic suppression and all-cause mortality. We hypothesized that receiving community-based HIV care is associated with better health outcomes.

\section{Methods}

\section{Data sources}

Data from eligible PLWH were extracted from the BC Centre for Excellence in HIV/AIDS (BC-CfE) Drug Treatment Program monitoring and evaluation system. Since October 1992, the distribution of antiretrovirals in $\mathrm{BC}$ has been the responsibility of the $\mathrm{BC}$-CfE. Antiretroviral drugs are distributed to all PLWH in $\mathrm{BC}$ according to specific guidelines generated by the Therapeutic Guidelines Committee. These guidelines have remained consistent with those put forward by the International AIDS Society-USA since 1996 [1, 2].

Eligible PLWH were cART naïve, $\geq 20$ years old, enrolled between January 1, 2003 and December 31, 2012 and followed: (1) until December 31, 2013 (if alive); (2) until the last contact date if they were lost to follow-up or if they moved out of $\mathrm{BC}$ ); or (3) until the date of death. These individuals started cART consisting of two nucleoside reverse-transcriptase inhibitors as backbone, plus either a non-nucleoside reverse-transcriptase inhibitor or a boosted protease inhibitor. They must also have had a CD4 count and plasma viral load measurement within six months of the initial antiretroviral date.

$\mathrm{BC}$ is a geographically large province with major regional differences in population demographic and socioeconomic characteristics, and in health needs. As such, the government divided the province in five health authorities (HA) [28], which are responsible for the management and delivery of health services in geographically defined subpopulations in BC. Typically, in the BC-CfE, physicians monitor PLWH on cART at intervals no longer than three months, at which time, prescriptions are renewed or modified, and PLWH' addresses are updated in the BC-CfE database. Every year, physicians are asked to update their addresses at the College of Physicians and Surgeons of $\mathrm{BC}$, and their addresses are continuously updated in our database. In this study, PLWH and their physician addresses were then used to classify individuals according to the five HAs where PLWH resided or where they received medical care.

To provide a context to the readers, the five BC HAs are heterogeneous regarding several socio-economic aspects including income, housing, employment, poverty, and ethnicity. These HAs are also heterogeneous in the way they deliver care to the BC population. In this study, we kept the name of these HAs anonymous for privacy reasons and we re-named these five regions as 1 to 5 . Based on the latest Regional Socio-Economic Index calculated by the $\mathrm{BC}$ government, HA 3 had by far the highest and HA 5 the lowest socio-economic index, while the other three HAs had very similar intermediate socio-economic indexes. It is also noteworthy that HA 3 has the highest number of clinical staff, prescribing physicians, comprehensive HIV supportive services and it hosts the BC-CfE.

\section{Outcome variables}

Crude, cART era and HA-specific all-cause mortality rates (per 1000 person-years of follow-up) were obtained for PLWH who have ever started treatment. These mortality rates were calculated dividing the number of deaths (all causes) by the number of person-years of follow-up; corresponding $95 \%$ confidence intervals and test for the equality for these rates were based on the Fisher's exact test [29]. Deaths occurring amongst PLWH during the follow-up period were identified on a daily basis from physician reports and through monthly record linkages carried out with the BC Vital Statistics Agency. 
Person-years for PLWH on treatment were calculated from the date of first cART to December 31, 2013, or the date of death or censoring.

cART era was defined according to the year of first treatment (2003-2007 and 2008-2012) and based on different treatment rollout periods in BC since 2003; with the most significant period being between 2009 and 2012 when the BC government funded the STOP HIV/ AIDS initiative to further address the HIV epidemic in the province [http://stophivaids.ca]. HAs 3 and 5 were the regions targeted by this initiative during the study period. Age-specific mortality rates were used to calculate life expectancies, and they were specifically obtained for the age groups $20-29,30-34,35-39,40-44,45-49$ and $50+$ years to account for the age distribution of PLWH in our cohort. The construction of these life tables and their respective $95 \%$ confidence intervals (CIs) were obtained as outlined in Chiang [30]. Additionally, we assessed whether these individuals were suppressed (i.e. a plasma viral load $<50$ copies $/ \mathrm{mL}$ ) based on the last viral load available during their follow-up. Note that all plasma viral load measurements in BC are centrally done at the St Paul's Hospital virology laboratory.

To correct the data for loss to follow-up, we built an explanatory multivariable logistic regression model (modeling the probability of death) among individuals whose status at the end of follow-up was either alive or dead. The final model contained the variables adherence, age, year of first cART, follow-up time, baseline CD4 cell count and plasma viral load. The area under the receiver operating characteristic curve (AUC-ROC), a measure of goodness of fit measuring the model's ability to discriminate between those PLWH who died and those who did not, ranges from 0.50 (no discrimination) to 1.00 (perfect discrimination) [31]. In this model, we obtained an AUC-ROC of 0.91, which is considered an outstanding discrimination. Therefore, we applied the estimated model coefficients to the data of PLWH who were lost to follow-up to calculate their respective probability of being dead by the end of followup. The cut-off used for these estimated probabilities was one and, in this case, only PLWH whose estimated probability was equal to one were considered dead at the end of follow-up. Given that these individuals do not have an exact date of death, we considered their last contact date as the date of death.

\section{Migration indicators}

For the migration analyses, we first calculated per-capita rates (per $100 \mathrm{PLWH}$ ever on cART) for each HA by dividing the number of PLWH by the number of physicians attending this population. This measure describes the heterogeneity in physician availability across the different HAs. We then defined migration for care as the movement from the HA where the PLWH resided to the HA that he/she received care. Note that this movement (within short and long distances) is temporary and may be for voluntary or involuntary reasons. A number of migration indicators were used to study the trends across HAs during 2003-2012 [32, 33]. First, we assessed internal migration of different HAs by comparing the HA where they received care to the HA where the PLWH resided. Second, we calculated three common migration rates for each HA defined as:

- In-migration rate: $\frac{I_{H A[i]}}{P_{H A[i]}} \times 1000$, where $I_{H A[i]}$ is the number of in-migrants during a specified time for the $i^{t h} \mathrm{HA}(i=1, \ldots, 5)$ and; $P_{H A[i]}$ is the population of the $i^{\text {th }} \mathrm{HA}$ at the mid-point of the migration interval. In lay terms, in this study, the in-migrants are the ones who leave the HA that they resided to receive care in another $\mathrm{HA}$.

- Out-migration rate: $\frac{O_{H A[i]}}{P_{H A[]}} \times 1000$, where $O_{H A[i]}$ is the number of out-migrants during a specified time for the $i^{t h} \mathrm{HA}(i=1, \ldots, 5)$ and; $P_{H A[i]}$ is defined above. In lay terms, in this study, the out-migrants are the ones arriving from different HAs to receive care in the HA that is not their residence.

- Net-migration rate: $\frac{I_{H A[i]}-O_{H A[i]}}{P_{H A[i]}} \times 1000$, where $I_{H A[i]}$, $O_{H A[i]}$ and $P_{H A[i]}$ are defined above.

All analyses were performed using SAS software version 9.3 (SAS, Cary, NC). The BC-CFE received approval for this study from the University of British Columbia ethics review committee at the St Paul's Hospital, Providence Health Care site (P05-123). The study complies with the BC's Freedom of Information and Protection of Privacy Act. The study was conducted primarily using anonymized administrative databases, and therefore informed consent was not required.

\section{Results}

\section{Baseline characteristics}

This study was based on data of 3653 PLWH who initiated cART for the first time in BC between 2003 and 2012. The baseline characteristics, summarized in Table 1, show that the majority of PLWH were male (82\%), had age between 25 and 44 years, initiated cART between 2009 and 2012, had baseline CD4 cell count between 50 and 349 cells $/ \mathrm{mm}^{3}$ and plasma viral load greater or equal to $5.00 \log _{10}$ copies $/ \mathrm{mL}$. The median follow-up of these individuals was 4.5 years $\left(25^{\text {th }}-75^{\text {th }}\right.$ percentile: $2.4-6.8$ years $)$.

\section{Migration patterns}

There is considerable heterogeneity in physician availability (i.e. per-capita rates per $100 \mathrm{PLWH}$ ever on cART) across all HAs. As illustrated in Fig. 1, when 
Table 1 Characteristics of the study population at the start of combination antiretroviral therapy from 2003 to 2012 in British Columbia

\begin{tabular}{|c|c|}
\hline Covariates and outcomes & $\begin{array}{l}\text { Frequency }(\%) \text { or } \\
\text { Median }\left(\mathrm{Q}_{1}-\mathrm{Q}_{3}\right)\end{array}$ \\
\hline \multicolumn{2}{|l|}{ Gender } \\
\hline Male & $2979(82 \%)$ \\
\hline Female & $674(18 \%)$ \\
\hline \multicolumn{2}{|l|}{ CART era } \\
\hline $2003-2007$ & $1554(43 \%)$ \\
\hline $2008-2012$ & $2099(57 \%)$ \\
\hline \multicolumn{2}{|l|}{ Age (years) } \\
\hline $20-24$ & $109(3 \%)$ \\
\hline $25-44$ & $2138(59 \%)$ \\
\hline $45-64$ & $1324(36 \%)$ \\
\hline $65+$ & $82(2 \%)$ \\
\hline \multicolumn{2}{|l|}{ CD4 cell count (cells $/ \mathrm{mm}^{3}$ ) } \\
\hline$<50$ & $421(12 \%)$ \\
\hline $50-199$ & $1154(32 \%)$ \\
\hline $200-349$ & $1172(32 \%)$ \\
\hline $350+$ & $906(25 \%)$ \\
\hline \multicolumn{2}{|l|}{ Viral load (log ${ }_{10}$ Copies/mL) } \\
\hline$<5.00$ & $1545(42 \%)$ \\
\hline $5.00+$ & $2108(58 \%)$ \\
\hline \multicolumn{2}{|c|}{ Adherence to therapy during the first year on cART (\%) } \\
\hline$\geq 95 \%$ & $2464(67 \%)$ \\
\hline $80-<95 \%$ & $501(14 \%)$ \\
\hline $40-<80 \%$ & $468(13 \%)$ \\
\hline $0-<40 \%$ & $220(6 \%)$ \\
\hline Follow-up (person-years) & $4.50(2.40-6.80)$ \\
\hline
\end{tabular}

CART combination antiretroviral therapy; $\mathrm{Q}_{1}$ stands for $25^{\text {th }}$ percentile; $\mathrm{Q}_{3}$ stands for $75^{\text {th }}$ percentile

physician availability was calculated according to the HA of PLWH residence, for every one physician, HA 1 had approximately 2.4 PLWH, HA 2 had 9.0, HA 3 had 10.3, HA 4 had 4.4 and HA 5 had 4.5. In contrast, when physician availability was calculated using the HA where PLWH received care, the per capita rates slightly dropped in all HAs with the exception of HA 2 which significantly dropped to 3.8 (57 \% decrease), HA 5 which dropped to 3.5 (21 \% decrease) and HA 3 which increased to 12.7 (23\% increase).

Table 2A shows the distribution of PLWH according to their residence and to where they received care during the study period. We observed that in HAs 1, 4, and 5, between 4 and $10 \%$ of PLWH migrated to HA 3 (i.e. the largest urban center) to receive care, and for HA 2 this proportion increased to $21 \%$. In HA 3, $77 \%$ of its PLWH residents remained in the same $\mathrm{HA}$ for their care.
Consequently, we obtained a negative net-migration rate of $-70.0,-75.8$, and -248.2 per $1000 \mathrm{PLWH}$ on cART for the HAs 1, 4 and 5, respectively, indicating that PLWH were leaving these HAs at a higher rate than staying in them (Table 2B). HA 3 had a netmigration rate of 186.6 per $1000 \mathrm{PLWH}$ on cART showing that this $\mathrm{HA}$ is absorbing most PLWH migrating for care across BC. Interestingly, HA 2 had the highest negative net-migration rate $(-1.334 .4)$, with most of its PLWH residents leaving to receive care in HA 3.

\section{Migration and HIV outcomes}

At the end of follow-up, we observed 421 deaths during 17430 person-years for a crude mortality rate 24.15 per 1000 person-years (95\% confidence interval (CI) 21.90 - 26.57). A total of $666(18 \%)$ PLWH were lost to follow-up, and of these, 157 (24\%) were LTFU because they moved out of $\mathrm{BC}$. After correcting the data for loss to follow-up, we re-coded $77 \mathrm{PLWH}$ as being dead at the end of follow-up. Thus, during follow-up there were 498 deaths for a (adjusted) crude mortality rate 28.57 per 1000 person-years (95 \% CI 26.12 - 31.19), and corresponding life expectancy (at the age 20 years) of 34.53 years (standard error 1.09) (Table 3).

As illustrated in Fig. 2, there was no statistically significant difference in suppression status among PLWH according to whether or not they received care in the HA of residence. We also calculated the mortality rate (per 1000 person-years) and life expectancy (at age 20 years) for each HA according to the patient and physician address during 2003-2012 (Table 3). When we used the patient's residence, HA 5 had the highest mortality rate (53.08) and the lowest life expectancy at age 20 years (19.41); HA 3 has the lowest mortality rate (25.84) and the highest life expectancy at age 20 years (37.66) in the province. When we classified PLWH according to the HA they received care, HA 5 was the only region that experienced the highest increase in mortality rate (62.99; $19 \%$ increase) and a higher decline in life expectancy at age 20 years $(17.35 ; 11 \%$ decrease). We found that HAs 1,2 , 3 and 4 had similar life expectancies regardless of where PLWH lived or sought care; however the same was not seen when we looked at the mortality rates in each of these regions. While the mortality rate in HAs 1 and 3 decreased to 36.15 (6\% decrease) and 24.72 (4\% decrease), respectively, the mortality rate in HAs 2 and 4 increased substantially to 31.09 (19\% decrease) and 39.10 (14\% decrease), respectively.

Figure 3 presents trends in mortality rates according to the cART expansion eras from 2003 to 2012. This figure also highlights the regions that were targeted by the STOP HIV/AIDS initiative (in green) and shows that the heterogeneity in mortality rates across 


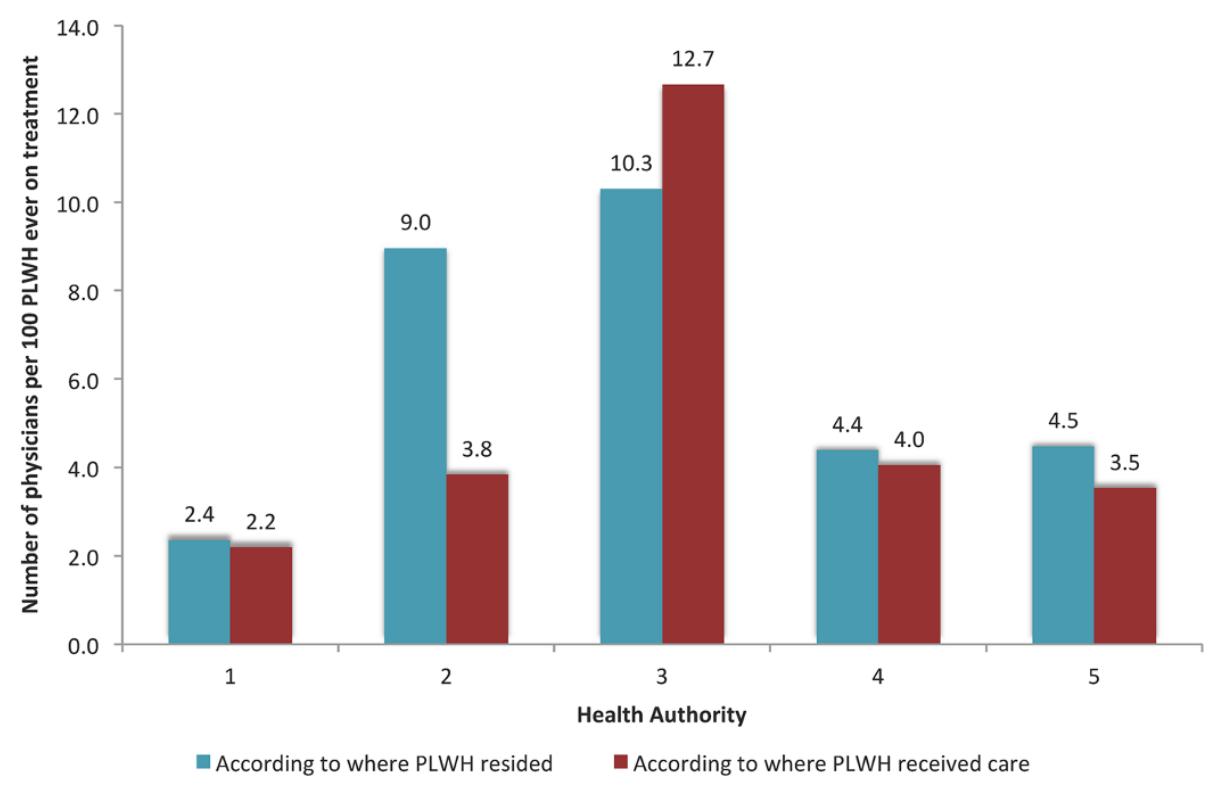

Fig. 1 Physician per capita rates by Health Authority in British Columbia from 2003 to 2012. PLWH stands for persons living with HIV

BC has decreased over time especially during 2009-2012 (coefficient of variation ranged from 0.49 (in 2003-2007) to 0.36 (in 2008-2012)). This decline was even more pronounced in the HAs initially targeted by the STOP HIV/ AIDS initiative, with the mortality rate in HA 3 dropping from 31.58 (in 2003-2007) to 17.01 (in 2008-2012) per 1000 person-years ( $46 \%$ decrease; $p$-value $<0.0001$ ); and HA 5 from 85.14 (in 2003-2007) to 30.28 (in 2008-2012) per 1000 person-years $(64 \%$ decrease; $p$-value $=0.0041)$. We also observed a significant decrease in HA 2 from 33.61 (in 2003-2007) to 14.40 (in 2008-2012) per 1000 person-years $(57 \%$ decrease; $p$-value $=0.0005)$.

\section{Discussion}

Our results demonstrate that there is a substantial heterogeneity in the number of PLWH seeking medical care outside the HA where they resided; between 4 and $21 \%$ of PLWH in each HA migrated to HA 3, which hosts the province's largest HIV care center. Although we investigated whether out-migration rates in these regions were due to physician availability, we observed that physicians working outside HA 3 were caring for fewer PLWH as many of their patients were seeking care in HA 3. Additionally, we assessed whether or not this migration for care was associated with health

Table 2 Inter-Health Authority migration rates per 1000 population in British Columbia from 2003 to 2012

\begin{tabular}{|c|c|c|c|c|c|c|}
\hline \multirow{2}{*}{$\begin{array}{l}\text { Health Authority where } \\
\text { PLWH received care }\end{array}$} & \multicolumn{6}{|c|}{ Health Authority where PLWH resided } \\
\hline & 1 & 2 & 3 & 4 & 5 & Total \\
\hline 1 & 145 & 6 & 39 & 6 & 1 & 197 \\
\hline 2 & 11 & 231 & 477 & 10 & 4 & 733 \\
\hline 3 & 19 & 65 & 2,027 & 37 & 6 & 2,154 \\
\hline 4 & 3 & 5 & 75 & 299 & 1 & 383 \\
\hline 5 & 6 & 7 & 30 & 4 & 129 & 176 \\
\hline Total & 184 & 314 & 2,648 & 356 & 141 & 3,643 \\
\hline Health Authority & Population at risk & In-Migrants & Out-Migrants & In-migration rate & Out-migration rate & Net-migration rate \\
\hline 1 & 184 & 39 & 52 & 212.0 & 282.6 & -70.7 \\
\hline 2 & 314 & 83 & 502 & 264.3 & $1,598.7$ & -1334.4 \\
\hline 3 & 2,648 & 621 & 127 & 234.5 & 48.0 & 186.6 \\
\hline 4 & 356 & 57 & 84 & 160.1 & 236.0 & -75.8 \\
\hline 5 & 141 & 12 & 47 & 85.1 & 333.3 & -248.2 \\
\hline
\end{tabular}

PLWH stands for persons living with HIV 
Table 3 Mortality rates and life expectancies for PLWH who have ever initiated combination antiretroviral therapy from 2003 to 2012 , stratified by Health Authority

\begin{tabular}{llllll}
\hline Mortality outcomes & Population size & Observed deaths & $\begin{array}{l}\text { Follow-up } \\
\text { (person-years) }\end{array}$ & $\begin{array}{l}\text { Mortality rate (95\% Cl) } \\
\text { per } 1000 \text { person-years }\end{array}$ & $\begin{array}{l}\text { Life expectancy at age } \\
20 \text { years (standard error) }\end{array}$ \\
\hline $\begin{array}{l}\text { British Columbia } \\
\text { Health Authority }\end{array}$ & 3653 & 498 & 17430 & $28.57(26.12-31.19)$ & $34.53(1.09)$ \\
where PLWH resided & & & & & $32.96(2.82)$ \\
1 & 198 & 36 & 937 & $38.42(26.91-53.19)$ & $34.36(2.67)$ \\
2 & 735 & 94 & 3591 & $26.18(21.15-32.03)$ & $37.66(1.53)$ \\
3 & 2155 & 266 & 10294 & $25.84(22.83-29.14)$ & $33.50(2.54)$ \\
4 & 386 & 66 & 1931 & $34.18(26.43-43.48)$ & $19.41(3.38)$ \\
5 & 179 & 36 & 678 & $53.08(37.19-73.51)$ & \\
Health Authority & & & & $36.15(24.73-51.05)$ & $34.74(2.96)$ \\
where PLWH received care & & 885 & $31.09(22.68-41.61)$ & $34.11(3.87)$ \\
1 & 184 & 32 & 1447 & $24.72(22.07-27.61)$ & $37.32(1.35)$ \\
2 & 314 & 45 & 12781 & $39.10(30.37-49.57)$ & $33.40(2.20)$ \\
3 & 2648 & 316 & 1739 & $62.99(43.35-88.44)$ & $17.35(3.67)$ \\
4 & 356 & 68 & 524 & &
\end{tabular}

PLWH stands for persons living with HIV

outcomes. We observed that while migrating to a larger center for HIV care (i.e. HA 3) was not associated with higher rates of viral load suppression; it was significantly associated with lower mortality rates, and slightly higher life expectancies. Finally, during the study period, we demonstrated that mortality rates decreased significantly in HAs 2, 3 and 5.

We hypothesized that receiving community-based HIV care would be associated with better outcomes, given the previous evidence from other chronic diseases which suggested that access to a local, continuous care provider was associated with better adherence to treatment, follow-up, and overall health [7-11]. Our findings are, therefore, in direct contrast to our initial hypothesis. There are a number of possible explanations for these discrepancies. First, there are potential confounding variables that may explain the association between migration and decreased mortality, such as the differential in

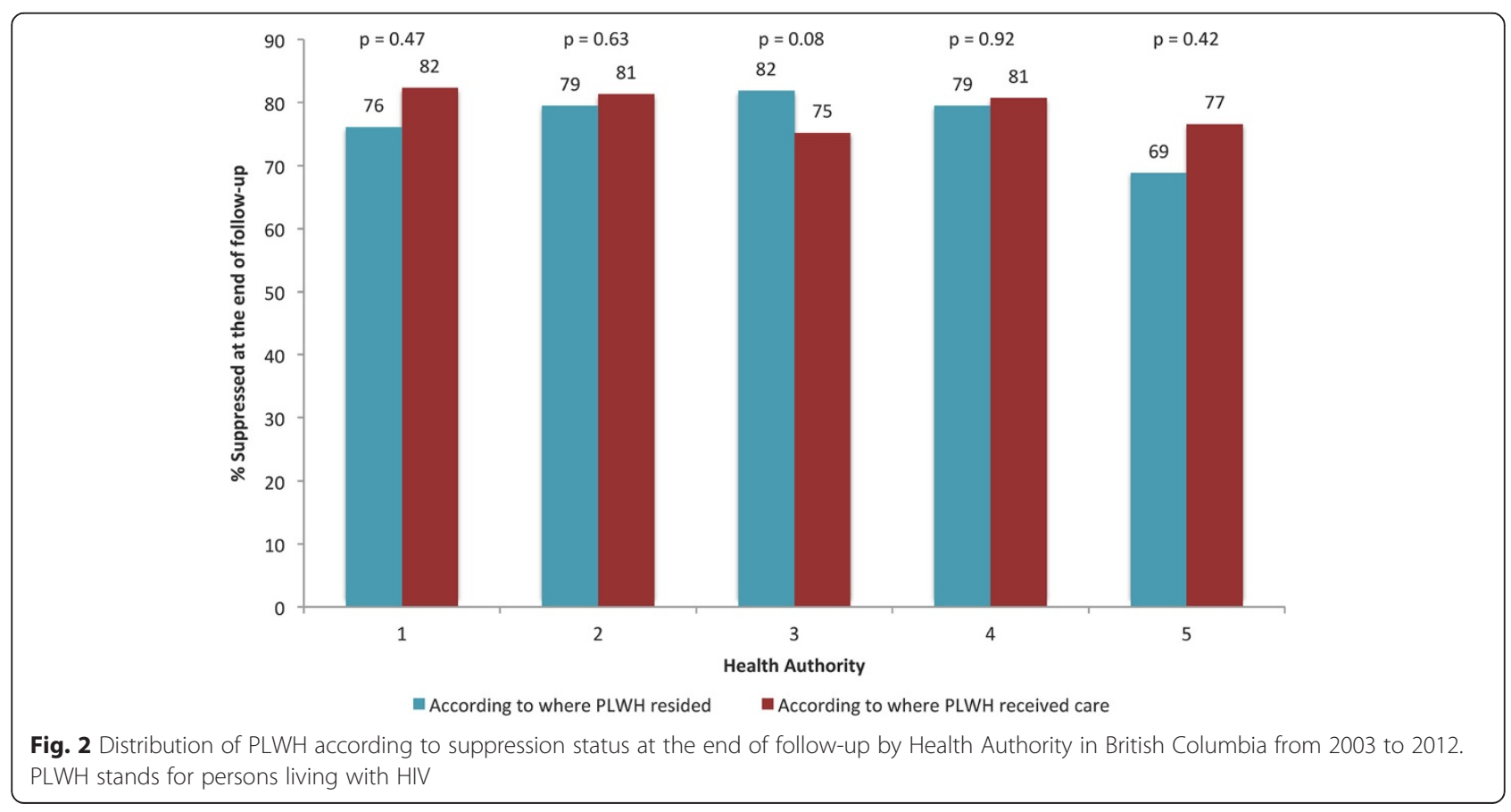



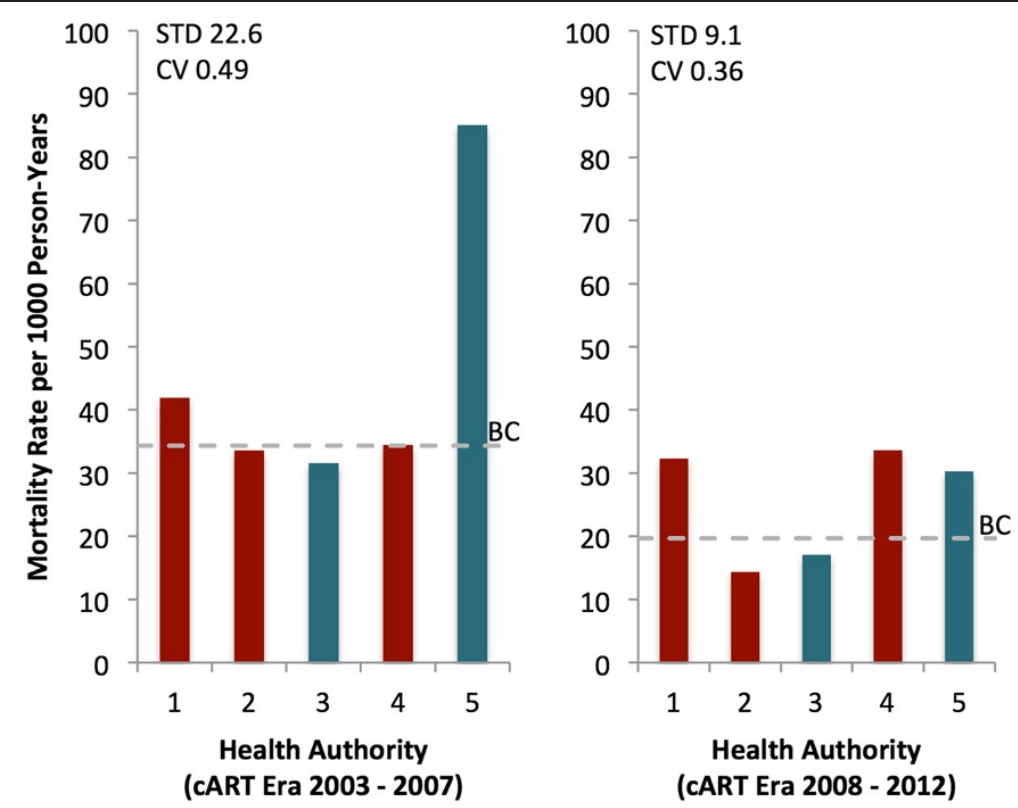

Fig. 3 Mortality rate by combination antiretroviral therapyera and by the Health Authority where the patient received care in British Columbia from 2003 to 2012. CART combination antiretroviral therapy; stands for PLWH stands for persons living with HIV; STD stands for standard deviation (higher values means more variation); CV stands for coefficient of variation (higher values means more variation). Red bars represent the Health Authorities that were not targeted by the intervention STOP HIV/AIDS, and green bars represent the Health Authorities targeted by this intervention

socio-determinants of health across HAs in BC. Additionally, it is common for PLWH to move to regions with larger centers for HIV care when they are really sick, and for these individuals to move back to their originating regions when they are close to dying [34]. Second, we assumed that the lower mortality associated with receiving care in the largest urban center in $\mathrm{BC}$ was mostly due to the larger availability of medical experts. It is important to mention that HA 3 also offers many nonmedical services for PLWH, such as housing, addictions and psychological support, as well as, support groups and peer networks. These other medical and non-medical services may partially explain the better outcomes seen in HA 3. Further studies will be needed to fully understand the reasons for this type of migration in $\mathrm{BC}$.

Our study has a number of important strengths. There are very few studies in resource-rich settings examining the association of migration among PLWH and health outcomes [10, 34-39]. This is the first study to demonstrate the relationship between migrating for HIV care and mortality during the modern CART era and within a treatment rollout program in BC. Also, we looked at a large sample of PLWH receiving care within a provincewide program, where all patients can access free medical attention, cART, and laboratory monitoring. Thus, it is unlikely that our results were influenced by sample size issues or biased by direct financial limitations to access medical care. It is also important to mention that delayed reporting of deaths was not likely a factor to influence our results, since most deaths were reported within one month through active follow-up with physicians and regular linkages to the BC Vital Statistics Agency. We also identified that a large number of PLWH are migrating to different HAs for care, and therefore, given that the life expectancy of PLWH is steadily increasing over time, the continual migration of these individuals can potentially overburden the resources of the receiving HAs. We believe that the results from this study can inform resource allocation in BC. Additionally, the methods used in this study can be further utilized to assess the impact of migration among PLWH in other settings around the world. Lastly, this study was possible since we maintain a state-of-art population-based database with detailed and up-to-date information on patient and physician addresses.

On the other hand, our study has a number of potential limitations. We did not control for physician experience since there is no gold-standard measure available for this purpose. We also did not expand our analyses to control for patient characteristics that may confound the relationship between migration for care and health outcomes. For example, it is well-known that for a patient to successfully supress their viral load, they must be diagnosed and initiated on CART in a timely basis, they need to maintain long-term optimal adherence to their treatment, and it is expected that they see their follow-up physician regularly to renew their cART prescriptions and monitor the safety and efficacy of their treatment [5]. The personal circumstances and attributes that allow a 
patient to meet these requirements, including financial resources, independence, and stability may have confounded our results. Additionally, these results may have been influenced by the perceived stigma/discrimination that some PLWH might experience in smaller communities $[19,25]$. Another limitation in these analyses relates to $18 \%$ of PLWH in our study being lost to follow-up. Although we adjusted our data by means of a highly predictive statistical model, we continue to conduct ongoing linkages with the BC Vital Statistics Agency to ascertain the health status of these individuals in our database. Finally, there are a number of ancillary non-medical services offered in larger treatment centres to PLWH that are not available in smaller centres, and these services are known to potentially impact health outcomes. However, it is unclear to what extent these services may explain the association between migration and study outcomes.

\section{Conclusions}

The current study revealed that a significant number of PLWH are migrating for care towards larger urban centers in $\mathrm{BC}$ and that this migration was associated with decreased mortality. These findings are in contrast to the experience in other chronic disease areas, and as such have important implications for health policy and resource allocation. Further research will be required to identify what factors are associated with migration for care, and whether these factors are independently protective against mortality. A thorough understanding of these issues will be critical to inform resource allocation aimed at optimizing the impact of cART.

\section{Competing interests}

Dr. Montaner has received limited unrestricted funding, paid to his institution, from Abbvie, Bristol-Myers Squibb, Gilead Sciences, Janssen, Merck, and ViiV Healthcare. Dr. Lima has received limited unrestricted funding, paid to her institution, from GlaxoSmithKline. The remaining authors have nothing to declare.

\section{Authors' contributions}

The author's contributions were as follows: Study concept and design: VDL; Acquisition of data: VDL, WC, JSGM, RSH; Analysis and interpretation of data: VDL; Drafting of the manuscript: VDL, NG Critical revision of the manuscript for important intellectual content and for final approval: VDL, NG, RSH, JSGM, LL, SG, RB, WC; Statistical analysis: VDL; Obtained funding: VDL, JSGM; Administrative, technical, or material support: VDL; Study supervision: JSGM, $\mathrm{RSH}$. All authors read and approved the final manuscript.

\section{Acknowledgements}

We would like to thank Kelly Hsu for administrative assistance, the patients enrolled in the British Columbia Centre for Excellence in HIV/AIDS and the physicians, nurses, social workers and volunteers who support them.

\section{Sources of funding}

Dr. Lima is supported by a grant the Canadian Institutes of Heath Research (CIHR; MOP-125948), by a Scholar Award from the Michael Institute for Health Research and a New Investigator award from CIHR. Dr. Montaner is supported with grants paid to his institution by the British Columbia Ministry of Health and by the US National Institutes of Health (R01 DA036307). The funding sources had no role in the choice of methods, the contents or form of this work, or the decision to submit the results for publication.

\section{Author details}

'British Columbia Centre for Excellence in HIV/AIDS, 608-1081 Burrard Street, Vancouver, BC, Canada V6Z 1Y6. 'Division of AIDS, Department of Medicine, Faculty of Medicine, University of British Columbia, Vancouver, BC, Canada V6Z 1Y6. ${ }^{3}$ Faculty of Medicine, University of Toronto, Toronto, ON, Canada M5S 1A8. ${ }^{4}$ Faculty of Health Sciences, Simon Fraser University, Burnaby, BC, Canada V5A 156

Received: 16 March 2015 Accepted: 4 September 2015

Published online: 14 September 2015

\section{References}

1. Carpenter CC, Fischl MA, Hammer SM, Hirsch MS, Jacobsen DM, Katzenstein DA, et al. Antiretroviral therapy for HIV infection in 1996. Recommendations of an international panel. International AIDS Society-USA. JAMA. 1996;276(2):146-54.

2. Gunthard HF, Aberg JA, Eron JJ, Hoy JF, Telenti A, Benson CA, et al. Antiretroviral treatment of adult HIV infection: 2014 recommendations of the International Antiviral Society-USA Panel. JAMA. 2014;312(4):410-25.

3. The Joint United Nations Programme on HIV/AIDS. 90-90-90 - An ambitious treatment target to help end the AIDS epidemic In. http://www.unaids.org/ sites/default/files/media_asset/90-90-90_en_0.pdf; 2014. Accessed 5 Dec 2014.

4. Thames AD, Moizel J, Panos SE, Patel SM, Byrd DA, Myers HF, et al. Differential predictors of medication adherence in HIV: findings from a sample of African American and Caucasian HIV-positive drug-using adults. AIDS Patient Care STDS. 2012;26(10):621-30.

5. Primary Care Guidelines Panel BC Centre for Excellence in HIV/AIDS. Primary Care Guidelines for the Management of HIV/AIDS in British Columbia. In. http://www.cfenet.ubc.ca/therapeutic-guidelines/primary-care; 2011. Accessed 5 Dec 2014.

6. Care and Support Challenges and Issues in a Spectrum of HIV/AIDS Affected Populations. [http///unw.cdnaids.ca/home.nsf/ad7c054e653c96438525721a0050fd60/ b32c62f9668a76160525732500678828/\$FILE/CBR_EN.pdf]. Accessed 5 Dec 2014.

7. Huntley A, Lasserson D, Wye L, Morris R, Checkland K, England H, et al. Which features of primary care affect unscheduled secondary care use? A systematic review. BMJ open. 2014;4(5):e004746.

8. Pichlhöfer $\mathrm{O}$, Maier $\mathrm{M}$. Unregulated access to health-care services is associated with overutilization-lessons from Austria. Eur J Public Health. 2015;25(3):401-3.

9. Teach SJ, Guagliardo MF, Crain EF, McCarter RJ, Quint DM, Shao C, et al. Spatial accessibility of primary care pediatric services in an urban environment: association with asthma management and outcome. Pediatrics. 2006;117(4 Pt 2):S78-85.

10. Horberg MA, Hurley LB, Towner WJ, Allerton MW, Tang BT, Catz SL, et al. Determination of optimized multidisciplinary care team for maximal antiretroviral therapy adherence. J Acquir Immune Defic Syndr. 2012;60(2):183-90.

11. Katon WJ, Lin EH, Von Korff M, Ciechanowski P, Ludman EJ, Young B, et al. Collaborative care for patients with depression and chronic illnesses. N Engl J Med. 2010;363(27):2611-20.

12. Grunfeld E, Fitzpatrick R, Mant D, Yudkin P, Adewuyi-Dalton R, Stewart J, et al. Comparison of breast cancer patient satisfaction with follow-up in primary care versus specialist care: results from a randomized controlled trial. $\mathrm{Br} J \mathrm{Gen}$ Pract. 1999:49(446):705-10.

13. Gardner EM, Daniloff E, Thrun MW, Reirden DH, Davidson AJ, Johnson SC, et al. Initial linkage and subsequent retention in HIV care for a newly diagnosed HIV-infected cohort in Denver, Colorado. J Int Assoc Provid AIDS Care. 2013;12(6):384-90.

14. Krentz $\mathrm{HB}$, Worthington $\mathrm{H}$, Gill MJ. Adverse health effects for individuals who move between HIV care centers. J Acquir Immune Defic Syndr. 2011;57(1):51-4

15. Marson KG, Tapia K, Kohler P, McGrath CJ, John-Stewart GC, Richardson BA, et al. Male, mobile, and moneyed: loss to follow-up vs. transfer of care in an urban African antiretroviral treatment clinic. PLoS One. 2013;8(10):e78900.

16. Perez Molina JA, Rillo MM, Suarez-Lozano I, Casado Osorio JL, Cobo RT, Gonzalez PR, et al. Do HIV-infected immigrants initiating HAART have poorer treatment-related outcomes than autochthonous patients in Spain? Results of the GESIDA 5808 study. Curr HIV Res. 2010;8(7):521-30. 
17. Saracino A, Tartaglia A, Trillo G, Muschitiello C, Bellacosa C, Brindicci G, et al. Late presentation and loss to follow-up of immigrants newly diagnosed with HIV in the HAART era. J Immigr Minor Health. 2014;16(4):751-5.

18. Shastri S, Sathyanarayna S, Nagaraja SB, Kumar AM, Rewari B, Harries AD, et al. The journey to antiretroviral therapy in Karnataka, India: who was lost on the road? J Int AIDS Soc. 2013;16:18502.

19. Taylor BS, Reyes E, Levine EA, Khan SZ, Garduno LS, Donastorg Y, et al. Patterns of geographic mobility predict barriers to engagement in HIV care and antiretroviral treatment adherence. AIDS Patient Care STDS. 2014;28(6):284-95.

20. Thierfelder C, Weber R, Elzi L, Furrer H, Cavassini M, Calmy A, et al. Participation, characteristics and retention rates of HIV-positive immigrants in the Swiss HIV Cohort Study. HIV Med. 2012;13(2):118-26.

21. Lankowski AJ, Siedner MJ, Bangsberg DR, Tsai AC. Impact of geographic and transportation-related barriers on HIV outcomes in sub-Saharan Africa: a systematic review. AIDS Behav. 2014;18(7):1199-223.

22. Gill VC, Krentz HB. Patient perspectives on leaving, disengaging, and returning to HIV care. AIDS Patient Care STDS. 2015;29(7):400-7.

23. Taylor BS, Garduno LS, Reyes EV, Valino R, Rojas R, Donastorg Y, et al. HIV care for geographically mobile populations. Mt Sinai J Med. 2011;78(3):342-51.

24. Govindasamy D, Ford N, Kranzer K. Risk factors, barriers and facilitators for linkage to antiretroviral therapy care: a systematic review. Aids. 2012:26(16):2059-67.

25. Pellowski JA. Barriers to care for rural people living with HIV: a review of domestic research and health care models. J Assoc Nurses AIDS Care. 2013;24(5):422-37.

26. Lima VD, Harrigan R, Murray M, Moore DM, Wood E, Hogg RS, et al. Differential impact of adherence on long-term treatment response among naive HIV-infected individuals. Aids. 2008;22(17):2371-80.

27. Lima VD, Lepik KJ, Zhang W, Muldoon KA, Hogg RS, Montaner JS. Regional and temporal changes in HIV-related mortality in British Columbia, 1987-2006. Can J public health = Revue canadienne de sante publique. 2010;101(5):415-9.

28. Ministry of Health. British Columbia Health Authorities. In. http://www.health. gov.bc.ca/socsec/about.html; 2014. Accessed 5 Dec 2014

29. Rothman KJ, Boice JD. Epidemiologic analysis with a programmable calculator: NIH publication, no. 79-1649. Washington, DC: U.S. Dept. of Health, Education, and Welfare, Public Health Service, National Institutes of Health; 1979.

30. Chiang CL. The life table and its construction. Introduction to Stochastic Processes in Biostatistics. New York: John Wiley and Sons; 1968. p. 189-214.

31. Hosmer DW, Lemeshow S, Sturdivant RX. Applied logistic regression. 3rd ed. New Jersey: John Wiley \& Sons, Inc; 2013.

32. Shryock H, Siegel J. The methods and materials of demography. Washington, DC: U.S. Department of Commerce: Bureau of Census; 1980.

33. Kpedekpo GMK. Essentials of demographic analysis for Africa. London, UK: Heinemann; 1982.

34. Lima VD, Druyts E, Montaner JS, Hogg RS. Regional and temporal trends in migration among people living with HIV/AIDS in British Columbia, 1993-2005. Can J of public health = Revue canadienne de sante publique. 2010;101(1):44-9.

35. Rachlis BS, Hogg RS, Wood E, Li K, Kerr T. Factors associated with geographic migration among a cohort of injection drug users. Health Place. 2008;14(3):536-43.

36. Rachlis BS, Wood E, Li K, Hogg RS, Kerr T. Drug and HIV-related risk behaviors after geographic migration among a cohort of injection drug users. AIDS Behav. 2010;14(4):854-61.

37. Wood E, Chan K, Montaner JS, Schechter MT, Tyndall M, O'Shaughnessy MV, et al. The end of the line: has rapid transit contributed to the spatial diffusion of HIV in one of Canada's largest metropolitan areas? Soc Sci Med. 2000;51(5):741-8

38. Wood E, Yip B, Gataric N, Montaner JS, O'Shaughnessy MV, Schechter MT, et al. Determinants of geographic mobility among participants in a population-based HIV/AIDS drug treatment program. Health Place. 2000;6(1):33-40.

39. Lima V, Fernandes K, Rachlis B, Druyts E, Montaner J, Hogg R. Migration adversely affects antiretroviral adherence in a population-based cohort of HIV/AIDS patients. Soc Sci Med. 2009;68(6):1044-9.

\section{Submit your next manuscript to BioMed Central and take full advantage of:}

- Convenient online submission

- Thorough peer review

- No space constraints or color figure charges

- Immediate publication on acceptance

- Inclusion in PubMed, CAS, Scopus and Google Scholar

- Research which is freely available for redistribution 